\title{
PENENTUAN POSISI SUMBER PROSPEK PANAS BUMI BERDASARKAN DATA ANOMALI MAGNETDI DAERAH AKESAHU, PULAU TIDORE, MALUKU UTARA
}

Oleh:

\author{
Rohima Wahyu Ningrum*
}

\begin{abstract}
ABSTRAK: Penelitian geofisika dengan menggunakan metode magnetik yaitu dengan alat Magnetometer Fluxgate. Luas daerah penyelidikan $\pm 1 \mathrm{~km} \mathrm{x} 1 \mathrm{~km}$, dibatasi oleh koordinat geografis antara $127^{\circ} 27^{\prime} 42^{\prime \prime} \mathrm{s} / \mathrm{d} 127^{\circ} 27^{\prime} 43^{\prime \prime} \mathrm{BT}$ dan $0^{\circ} 43^{\prime} 17^{\prime \prime} \mathrm{s} / \mathrm{d} 0^{\circ} 43^{\prime} 19^{\prime \prime} \mathrm{LU}$. Penelitian ini bertujuan untuk mengetahui posisi sumber prospek panas bumi di daerah Akesahu, Pulau Tidore berdasarkan data anomali medan magnet. Data medan magnet total yang terukur adalah medan utama, medan luar dan medan anomali. Untuk menghilangkan efek-efek anomali dari medan magnet luar dan anomali medan magnet utama dilakukan perhitungan koreksi variasi harian, koreksi $d r i f t$ (kesalahan alat), koreksi penyesuaian, koreksi IGRF, dan pemisahan anomali residual dan regional. Hasil penelitian menunjukkan bahwa, daerah Akesahu, Pulau Tidore memiliki potensi panas bumi yang masih cukup besar yang ditandai dengan adanya manifestasi panas bumi berupa mata air panas. Anomali medan magnet daerah Akesahu ditunjukkan dengan adanya anomali yang rendah ( 0.90 sampai dengan -2163.09 nT) yang memanjang arah utara-selatan di bagian Timur Pulau Tidore. Disamping itu di sekitar mata air panas Akesahu secara geologis didukung dengan adanya empat buah sesar normal. Ini sebagai sistem pengontrol panas bumi yang lainnya di Pulau Tidore.
\end{abstract}

Kata kunci: Panas bumi, Magnetik, Akesahu

\begin{abstract}
Geophysical studies using magnetic method was by means of fluxgate magnetometer. The area of investigation was $\pm 1 \mathrm{~km} \mathrm{x} 1 \mathrm{~km}$, laid over between $127^{\circ} 27$ ' 42 "s / d $127^{\circ} 27^{\prime} 43^{\prime \prime} \mathrm{E}$ and $0^{\circ} 43^{\prime} 17^{\prime \prime s} / \mathrm{d} 0^{\circ} 43^{\prime} 19^{\prime \prime} \mathrm{N}$ in geographic coordinates. This study aims to determine position of the prospect of geothermal source in Akesahu, Tidore Island based on magnetic anomaly data. The measured total magnetic field data were the main field, the external field and the anomalies field. It was calculated daily variation correction, drift correction (instrument error), adjustment correction, IGRF correction, and the separation of residual and regional anomalies to eliminate the effects of the external magnetic field anomalies and anomalies main magnetic field. The results presented that Akesahu and Tidore Island have geothermal potential which is still quite large characterized by the existence of geothermal manifestations such as hot springs. Akesahu anomalous magnetic field area shown by the low anomaly (up to $-2163.090 .90 \mathrm{nT}$ ) which extends north-south in the eastern part of the island of Tidore. Moreover, around Akesahu hot springs is geologically supported by the four normal faults. These geothermal system are as main controller on Tidore island.
\end{abstract}

Keywords: Geothermal, Magnetic, Akesahu

\footnotetext{
*Program Studi Pendidikan Fisika Fakultas Keguruan dan Ilmu Pendidikan Universitas
} Khairun (Email: rohima_wn@yahoo.co.id) 


\section{PENDAHULUAN}

Indonesia merupakan negara kepulauan yang mempunyai tingkat aktivitas tektonik dan vulkanik yang cukup tinggi. Aktivitas tektonik dan vulkanik ini disebabkan karena posisi gugusan kepulauan Indonesia yang berada pada pertemuan antar lempeng tektonik. Secara geografis Indonesia terletak diantara pertemuan antara 3 lempeng besar tektonik (megatriple junction), yakni Lempeng Indo-Australia, Eurasia, dan Pasifik seperti yang ditunjukkan pada gambar 1 (1), dan beberapa lempeng kecil lainnya seperti Sangihe, Maluku dan Halmahera seperti yang ditunjukka pada Gambar 2. Lempeng tektonik terbentuk oleh kerak benua (continental crust) ataupun kerak samudra (oceanic crust), dan lapisan batuan teratas dari mantel bumi (earth's mantle). Interaksi antar lempeng tersebut membentuk jalur subduksi di busur luar kepulauan Indonesia. Sementara pada busur dalam kepulauan terdapat busur vulkanik aktif.

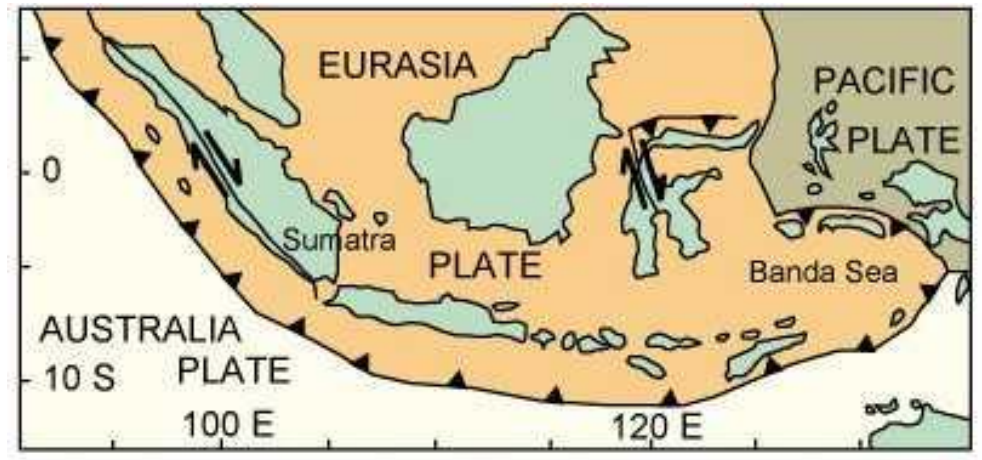

Gambar 1. Konfigurasi lempeng tektonik di Indonesia (1).

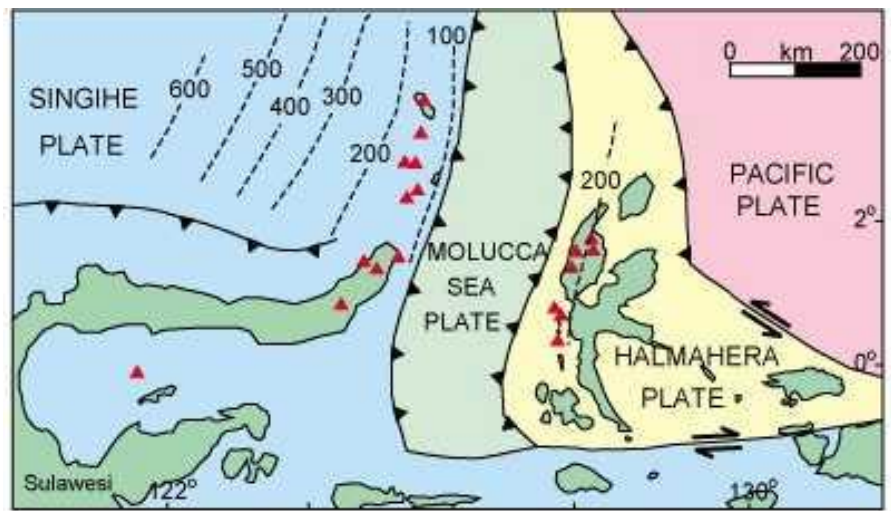

Gambar 2. Konfigurasi lempeng tektonik dan penyebaran gunungapi di daerah Halmahera - Sulawesi Utara (2).

Proses terbentuknya busur vulkanik inilah yang menjadidasar besarnya energi panas bumi yang terkandung di Indonesia. Energi panas bumi adalah energi sumber daya alam berupa air panas atau uap yang terbentuk dalam reservoir di dalam bumi melalui pemanasan air bawah permukaan oleh batuan beku panas (3). Metode geofisika yang digunakan dalam penelitian ini adalah metode magnetik. Pengukuran data magnetik yang didapat dari hasil pengukuran didasarkan pada sifat batuan berupa kerentanan magnet batuan (magnetic suseptibility). Kerentanan magnet batuan $(k)$ memiliki hubungan yang 
kuat dengan temperatur, dimana sifat kemagnetan batuan akan hilang di atas suhu Curie $\left(700^{\circ} \mathrm{C}\right)$. Sedangkan batuan reservoar panas bumi umumnya bertemperatur $<600^{\circ} \mathrm{C}$ sehingga sifat kemagnetan belum hilang (4).

Gunung Matubu terdapat di Pulau Tidore Provinsi Maluku Utara yang dahulunya merupakan salah satu daerah vulkanik dan kaya akan batuan beku.Sumber mata air panas banyak ditemukan Dowora, Tomado, Tanjung Putus, Akesahu Gulili dan Akesahu. Dapat diperkirakan bahwa batuan beku di daerah tersebut mengalami proses alterasi.

Berdasarkan dari uraian latar belakang adapun perumusan masalah yang dapat disimpulkan adalah Bagaimanakah informasi posisi sumber prospek panasbumi di daerah Akesahu,Pulau Tidore berdasarkan data anomali medan magnet. Tujuan penelitian ini adalah untuk mengetahui informasi posisi sumber prospek panas bumi di daerah Akesahu, Pulau Tidore berdasarkan data anomali medan magnet. Penelitian ini dibatasi pada pengolahan dan interpretasi kualitatif data anomali medan magnet.

Kontribusi penelitian ini adalah untuk memperoleh informasi posisi mengenai prospek panas bumi di daerah Akesahu, Pulau Tidore, sehingga dapat menjadi referensi penelitian selanjutnya dan diharapkan nantinya akan ada pengembangan terutama untuk pembangkit listrik tenaga panasbumi (PLTPb).

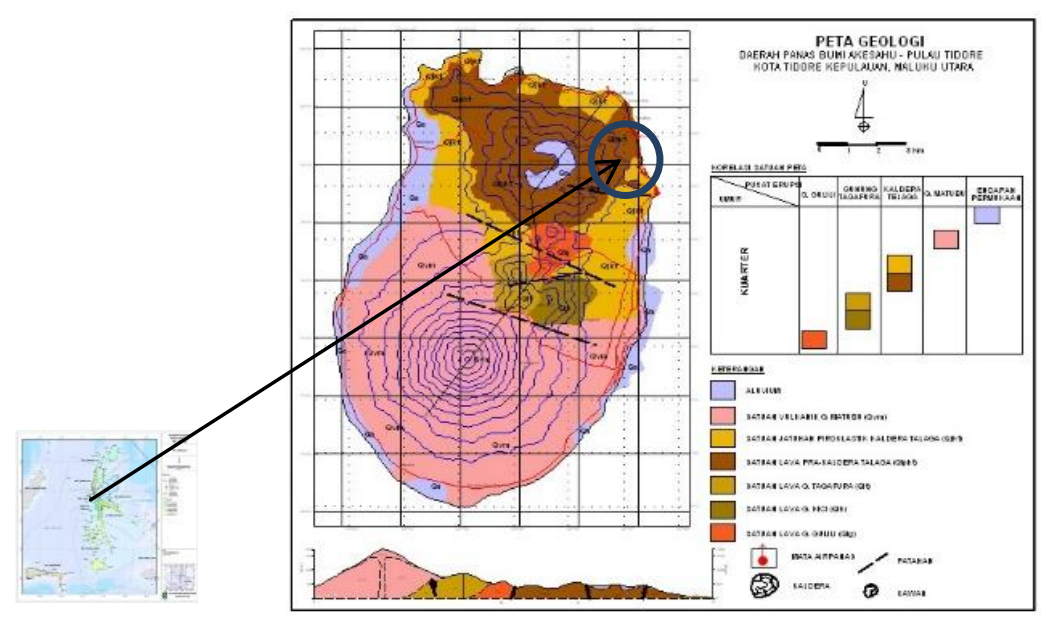

Gambar 3. Lokasi Penelitian berdasarkan peta geologi (PSDG, 2005)

Pengambilan data dilakukan di daerah Akesahu, Pulau Tidore. Secara administratif, daerah survei berada di daerah Akesahu, Pulau Tidore Provinsi Maluku Utara. Luas daerah penyelidikan $\pm 1 \mathrm{~km}$ x $1 \mathrm{~km}$, dibatasi oleh koordinat geografis antara $127^{\circ} 27^{\prime} 42^{\prime \prime} \mathrm{s} / \mathrm{d}$ $127^{\circ} 27^{\prime} 43^{\prime \prime} \mathrm{BT}$ dan $0^{\circ} 43^{\prime} 17^{\prime}$ ' s/d 0 $0^{\circ} 43^{\prime} 19$ ' LU seperti tampak pada Gambar 3.

Peralatan yang digunakan dalam penelitian ini terdiri dari: Magnetometer Fluxgate, GPS (Global positioning system), Peta (peta geologi, peta topografi, dan peta digital Rupa Bumi Pulau Tidore), Kompas, Meteran, Handy Talky (HT) alat komunikasi, Komputer beserta software Surfer 8.0, Fortran for Windows, Microsoft Excel,danCoordTrans 2005.10.

Metode yang digunakan dalam penelitian ini adalah metode Geofisika, yaitu metode magnetik. Data yang diperoleh dari hasil pengukuran di lapangan dihitung untuk mendapatkan medan magnet total dari komponen medan magnet vertikal dan medan 
magnet horizontal. Data medan magnet total yang terukur terdiri dari medan utama, medan luar dan medan anomali, maka untuk menghilangkan efek-efek anomali dari medan magnet luar dan anomali medan magnet utama dilakukan perhitungan koreksi-koreksi sebagai berikut: koreksi variasi harian, koreksi drift (kesalahan alat), koreksi penyesuaian, koreksi IGRF, dan pemisahan anomali residual dan regional.

\section{HASIL DAN PEMBAHASAN}

Hasil pengukuran magnetik difokuskan pada pesisir pantai daerah Akesahu, Pulau Tidore, dimana terdapat sumber airpanas dipermukaan. Proses perhitungan data magnetik dilakukan sampai tahap interpretasi, untuk mendapatkan harga intensitas medan magnet total yang dihasilkan oleh batuan dibawah permukaan pada daerah penelitian. Sehingga dapat menginterpretasi daerah potensi panas bumi di daerah Akesahu.

Proses pengolahan data melalui beberapa koreksi, hal ini dilakukan agar nilai anomali magnetik tidak terpengaruh dengan medan magnet luar. Koreksi pertama yang dilakukan adalah koreksi variasi harian, hal ini dikarenakan sering terjadi perubahan medan magnet bumi setiap saat karena adanya perubahan kelistrikan pada atmosfir disekitar daerah penyelidikan dan perubahan posisi bumi, bulan dan matahari yang juga memiliki medan magnet sendiri.

Setelah dilakukan koreksi variasi harian selanjutnya adalah koreksi drift (kesalahan alat) dan koreksi penyesuaian terhadap harga medan magnet total pada base station dengan medan magnet di field. Kemudian menyeragamkan nilai-nilai medan magnetik utama bumi dengan koreksi IGRF, dikarenakan medan magnet utama bumi sering berubah terhadap waktu.

Data anomali magnet yang diperoleh dapat ditampilkan berupa peta kontur anomali magnet total dengan menggunakan program Surfer 8.0 seperti (Gambar 4).

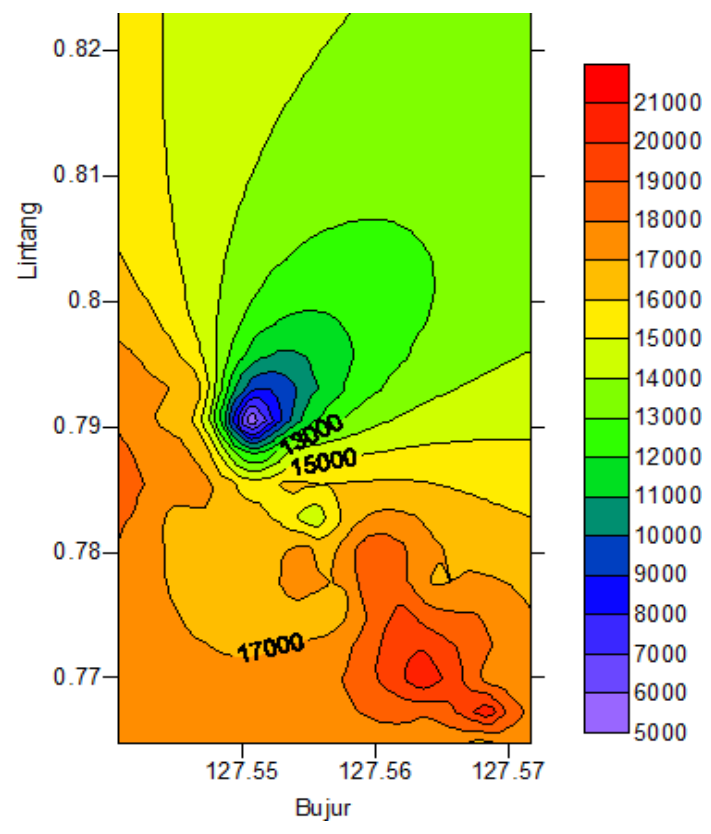

Gambar 4. Kontur anomali magnet total 
Nilai anomali magnetik yang diperoleh kemudian dilakukan pemisahan anomali residual dari anomali regional. Anomali residual diperoleh dengan mereduksi anomali medan magnet total terhadap nilai anomali regional. Hal ini dilakukan dengan tujuan untuk menghilangkan pengaruh yang disebabkan oleh anomali regional yang lebih luas. Sehingga diperoleh bentuk kontur anomali residual seperti Gambar 5.

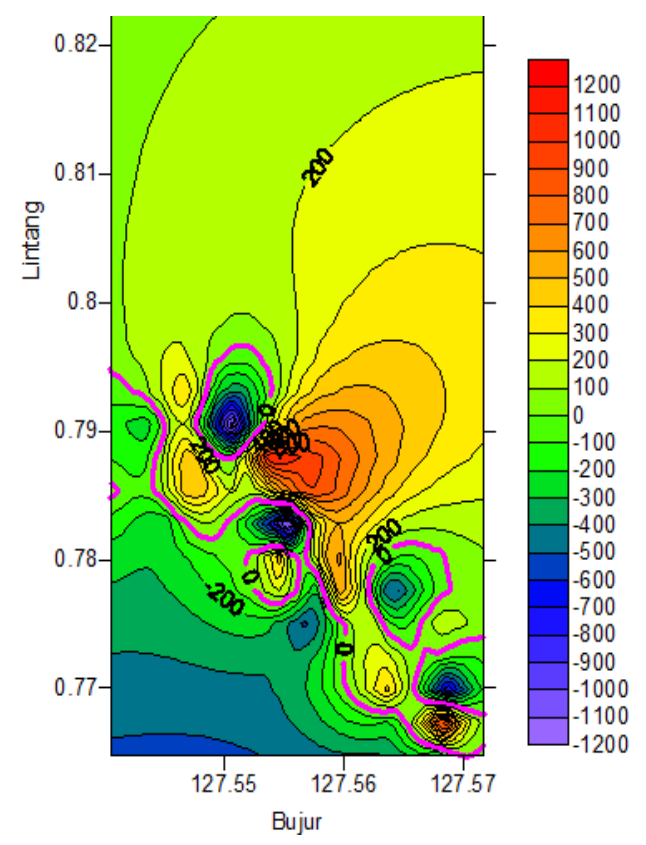

Gambar 5. Kontur anomali medan magnet residual

Pada penelitian panas bumi data anomali magnetik yang diinginkan adalah anomali magnetik yang rendah. Hal ini dikarenakan anomali magnetik rendah tersebut sangat berkaitan dengan demagnetisasi batuan akibat panas yang dilepaskan dari suatu sumber panas bumi.

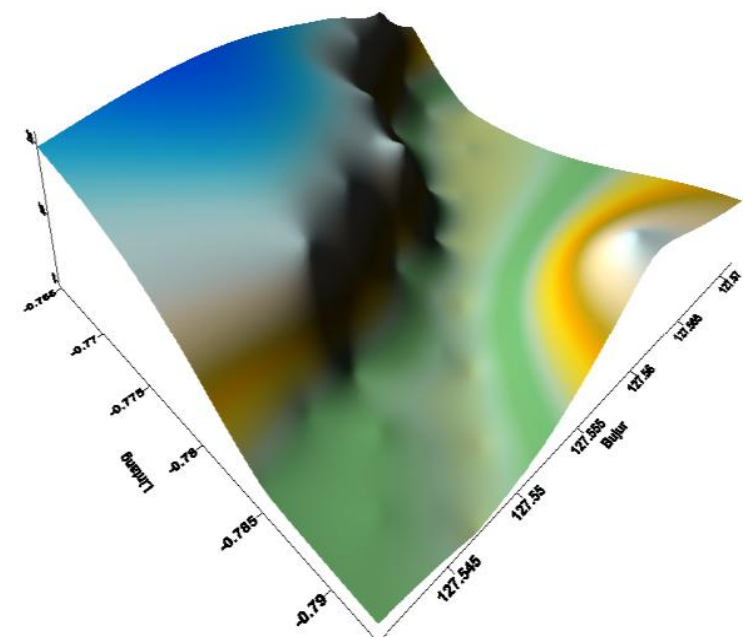

Gambar 6. Topografi daerah penelitian (3Dimensi)

Dilihat dari segi geologinya daerah Pulau Tidore banyak mengandung batuan Gunung api Holosen (Qhv) dan Batuan aluvium (Qal). Batuan vulkanik banyak tersingkap pada kelurusan-kelurusan gunungapi yang berarah timurlaut - baratdaya. Kelurusan ini 
berupa struktur dike / terobosan yang memotong hingga batuan dasar. Sedangkan batuan aluvium tersingkap dipinggir pantai dan daerah pedataran seputar Pulau Tidore (5).

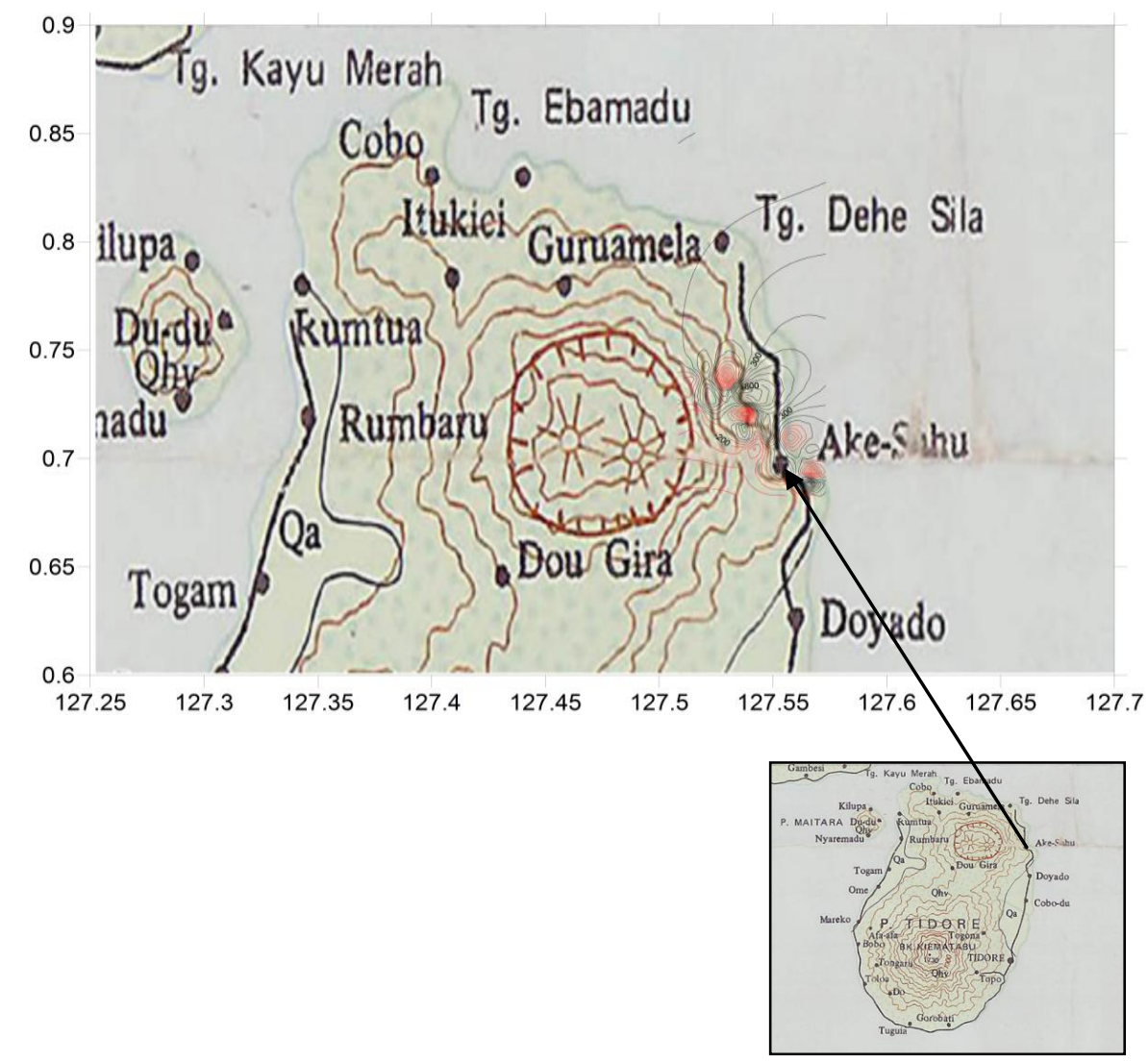

Gambar 7 . Peta anomali residual daerah Akesahu Akesahu-P.Tidore

Di daerah Akesahu, pulau Tidore terdapat batuan Gunung api Holosen. Batuan ini berupa breksi andesit, lava andesit-basal, dan tufa. Kedua batuan tersebut, yakni breksi andesit dan lava andesit-basal memungkinkan menyimpan sisa panas dari dapur magma. Peran dari gunungapi ini ditunjang dengan adanya 4 struktur sesar normal yang memanjang dengan arah baratlaut - timur tenggara. Struktur inilah yang mengontrol pemunculan manifestasi panas bumi yang ada di daerah penyelidikan sehingga terbentuk sumber mata air panas Akesahu.

Dalam penelitian ini, interpretasi dilakukan dengan cara kualitatif, hasil ini memberikan informasi dari posisi sumber anomali. Interpretasi kualitatif dilakukan dengan menganalisa peta kontur anomali magnetik dengan hasil yang diperoleh berupa lokasi benda penyebab anomali berdasarkan klostur kontur. Dari peta kontur diperoleh bahwa ada klostur kontur benilai negatif dan bernilai positif.

Dalam penelitian airpanas disini, anomali magnet rendah yang dibutuhkan sedangkan untuk anomali sedang sampai tinggi dalam penelitian ini dibaikan. Hal ini diketahui bahwa anomali magnetik yang rendah ini sangat berkaitan dengan demagnetisasi batuan akibat panas yang dilepaskan dari suatu sumber panas bumi dan merepresentasikan daerah tersebut masih memiliki potensi panas bumi yang cukup besar. Dari hasil peta kontur anomali magnet residual yang memiliki nilai anomali yang rendah sekitar 0.90 sampai 
dengan -2163.09 nT, sehingga bisa diketahui bahwa daerah Akesahu masih memiliki potensi sumber panasbumi yang cukup besar.

Hubungan secara geologi dan hasil peta kontur di daerah Akesahu diketahui bahwa daerah tersebut ditempati oleh batuan lava andesit Pra Kaldera Talaga,piroklastik Talagadan piroklastik Kimatubu. Mata airpanas Akesahu dipengaruhi oleh keberadaan sesar yang membuat daerah tersebut menjadi dua blok/patah (blok naik dan turun).

\section{KESIMPULAN}

Berdasarkan hasil yang diperoleh, maka dapat disimpulkan bahwa:

1. Daerah Akesahu, Pulau Tidore memiliki potensi panas bumi yang masih cukup besar dan ditandai dengan ditemukannya manifestasi panas bumi berupa mata air panas.

2. Hasil interpretasi kualitatif anomali medan magnet daerah Akesahu menunjukkan terdapat anomali yang rendah (0.90 sampai dengan -2163.09 nT) dan memanjang arah utara-selatan di bagian Timur Pulau Tidore.

3. Dilihat dari kondisi geologi hal ini didukung oleh terdapatnya empat buah sesar normal disekitar mata air panas Akesahu, dan sebagai pengontrol sistem panas bumi yang lainnya di Pulau Tidore.

\section{DAFTAR PUSTAKA}

(1) Katili J A. Volcanism and Plate Tectonics in The Indonesia Island arcs, Tectonographysics. 1973.165-188.

(2) Hamilton W B. Tectonics Map of Indonesia, a progress report U.S. Geol. Colarado : Surv. Denver. 29 pp. 1979.

(3) Tim Pertamina. Peluang Pemanfaatan Potensi Energi Geothermal Ulubelu Lampung. Makalah Workshop Geofisika Universitas Lampung. Bandar Lampung. 2007.

(4) Rasimeng S. Interpretasi Data Anomali Magnetik Turunan Vertikal Orde Dua Untuk Menentukan Posisi Sumber Pana sbumi di Daerah Gunung Api Ungaran. Thesis. Yogjakarta: PPS UGM. 2003

(5) Tim Penyelidikan Panas bumi Akesahu. Penyelidikan Panasbumi Akesahu Maluku Utara. Bandung : Pusat Sumber Daya Geologi. 2005. 